\title{
Effect of Clay-Mineral Composition on Flexural Strength of Clay-based Membranes
}

\author{
Young-Il Lee, Jung-Hye Eom*, ${ }^{\star}$, Young-Wook Kim*, and In-Hyuck Song** \\ Department of Optometry and Vision Science, Dongnam Health College, Suwon 440-714, Korea \\ *Functional Ceramics Laboratory, Department of Materials Science and Engineering, The University of Seoul, \\ Seoul 130-743, Korea \\ **Engineering Ceramics Group, Korea Institute of Materials Science, Changwon 642-831, Korea \\ (Received July 29, 2014; Revised August 27, 2014; Accepted August 28, 2014)

\section{점토 광물 조성이 점토기반 분리막의 곡강도에 미치는 영향 \\ 이영일 · 엄정혜*† · 김영욱* · 송인혁** \\ 동남보건대학교 안경광학과 \\ *서울시립대학교 신소재공학과 기능성세라믹스연구실 \\ **재료연구소 엔지니어링세라믹연구그룹} \\ (2014년 7월 29일 접수 ; 2014년 8월 27일 수정 ; 2014년 8월 28일 채택)
}

\begin{abstract}
Clay-based membranes with submicron pore size were successfully prepared by a simple pressing process using low-cost starting materials(e.g., kaolin (K), bentonite (B), talc (T), and sodium borate). The green bodies were sintered at $1000^{\circ} \mathrm{C}$ for $2 \mathrm{~h}$ in air. The effect of clay-mineral composition on the flexural strength of clay-based membranes was investigated. The porosity of the clay-based membranes could be controlled within the range of $34-42 \%$ by adjusting the starting composition. The flexural strength of the lowcost membranes depended on both the porosity and the $\alpha$-quartz content. In turn, the porosity and $\alpha$-quartz content were affected by the $(\mathrm{B}+\mathrm{T}) /(\mathrm{K}+\mathrm{B}+\mathrm{T})$ ratio. The plot of strength relative to this ratio, showed a maximum when the ratio was 0.4 . The typical flexural strength of these clay-based membranes (with ratio 0.4 ) was $28 \mathrm{MPa}$ at $34 \%$ porosity.
\end{abstract}

Key words : Clay, Membranes, Porosity, Strength, Additive

\section{1. 서 론}

지구 온난화 등의 이상 기후 문제가 대두되면서 전 세 계적으로 물부족을 대비하기 위해 대체수자원 개발에 대 한 관심이 증가되고 있다. 대체수자원들 중에서도 하수재 이용은 그 접근성이 용이하고 일정한 공급량과 수질을 얻 을 수 있다는 점에서 가장 적합한 수원으로 인식되고 있 다. 이에 기존 재이용을 위한 공정은 생물처리 및 응집/ 침전과 같은 화학처리 등의 다양한 수처리 기술들을 조 합한 시스템이었으나, 수질기준이 강화됨에 따라 멤브레 인 공정의 적용이 주목 받고 있다. 최근에는 기존 고분자 분리막의 산성과 염기성에 약한 화학적 특성의 단점이 보 완된 세라믹 분리막이 주목을 받고 있다. 다공질 세라믹 스는 기존의 치밀한 재료가 갖지 못하는 저장, 단열, 경

${ }^{\dagger}$ Corresponding author : Jung-Hye Eom

E-mail : junghye-um@uos.ac.kr

Tel : +82-2-6490-5776 Fax : +82-2-6490-2404
량, 통기성, 높은 비표면적 (specific surface area) 등의 특 성을 갖고 있기 때문에 수처리용 분리막으로 사용되고 있 다. 이러한 다공질 세라믹스의 물성은 기공의 형상, 크기, 기공률, 배향성 및 기공벽의 미세조직 등에 의해 영향을 받으므로, 이러한 특성의 제어는 수처리용 세라믹 분리막 의 물성 향상 및 응용에 있어서 매우 중요한 연구 분야 이다. ${ }^{1-10)}$

일반적으로 세라믹 분리막은 지르코니아, 알루미나 및 티타니아를 주원료로 사용하여 제조되었고, 이와 관련하 여 많은 연구들이 진행되었다. ${ }^{11-13)}$ 하지만, 세라믹 분리 막의 우수한 화학적, 물리적 특성에도 불구하고, 고가의 원료비용 및 제조와 관련된 공정으로 그 응용은 제한되 었다. 이에 경제적인 세라믹 분리막을 개발하기 위해 경 제적인 자연 친화적 소재인 카올린을 주원료 활용한 연 구들이 진행되고 있다. ${ }^{14-16)}$ 멤브레인 시장은 2017년 76억 달러로 연평균 $9 \%$ 의 성장을 전망하고 있으며, ${ }^{17-19)}$ 전 세 계적으로 인구증가, 도시화, 산업화, 기후변화 등으로 물 부족이 심화되고 있어, 수처리 분야의 성장이 가장 돋보 
일 것으로 전망되어 비용효율이 높은 자연친화적 세라믹 스 멤브레인의 특성과 성능을 제어하는 제조공정의 연구 는 미래 산업발전에 중대한 관심사로 대두될 것이다.

따라서 본 연구는 소듐보레이트를 첨가제로 사용하고, 비용 효율이 높고 자연친화적인 점토기반 분리막에서 벤 토나이트와 활석의 조성이 분리막의 곡강도에 미치는 영 향을 고찰하였다. 이를 통해 기존 세라믹 분리막의 단점 인 고비용 문제점을 해결하고, 다양한 수처리 산업 분야 에 저가의 점토질 기반 분리막을 적용하는 방안을 모색 하고, 향후 연관 산업분야에도 기술적 배경을 제공하고자 하였다.

\section{2. 실험 방법}

출발원료로 카올린 $\left(\mathrm{Al}_{2} \mathrm{O}_{3} \cdot 2 \mathrm{Si}_{2} \cdot 2 \mathrm{H}_{2} \mathrm{O}\right.$, extra pure, Samchun Pure Chemical Co. Ltd., Pyongtak, Korea), 벤토나 이트 (chemical pure, Yakuri Pure Chemicals C. Ltd., Kyoto, Japan), 활석 ( $3 \mathrm{MgO} \cdot 4 \mathrm{SiO}_{2} \cdot \mathrm{H}_{2} \mathrm{O}$, chemical pure, Samchun Pure Chemical Co. Ltd., Pyongtak, Korea), 소듐보레이트 $\left(\mathrm{Na}_{2} \mathrm{~B}_{4} \mathrm{O}_{7} \cdot 10 \mathrm{H}_{2} \mathrm{O}\right.$, Samchun Pure Chemical Co., Ltd., Pyongtak, Korea)를 출발원료로 사용하였으며, 실험에 사용된 원 료의 화학조성은 Table 1에 나타내었다. 소듐보레이트는 결합제 역할로 점토기반 멤브레인의 기계적 강도를 증가 시키기 위해 $2 \mathrm{wt} \%$ 첨가하였다. ${ }^{20)}$ 성형공정의 결합제로 polyethylene glycol $(\mathrm{PEG})$ 을 추가로 첨가하였다. 각각의 원료 조합은 증류수를 용매로 사용하여 습식으로 혼합하 였다. 혼합은 $\mathrm{Al}_{2} \mathrm{O}_{3}$ 볼과 폴리프로필렌 용기를 사용하여 3 시간 동안 볼 밀링 (ball milling) 한 후, 완전히 건조시켰 다. 혼합된 분말은 $35 \mathrm{~mm} \times 8 \mathrm{~mm} \times 4 \mathrm{~mm}$ 크기의 시편으 로 상온에서 $50 \mathrm{MPa}$ 의 압력으로 일축가압성형 하였다. 제 조된 성형체는 전기로를 사용하여 $3{ }^{\circ} \mathrm{C} / \mathrm{min}$ 의 승온속도로 $1000^{\circ} \mathrm{C}$ 에서 공기 분위기를 사용하여 2시간 동안 소결하 였다. 제조된 시편의 부피밀도 (bulk density, $\mathrm{D}_{\mathrm{b}}$ )는 질량 (M) 대 부피 $(\mathrm{V})$ 비로부터 계산하였고, 시편의 기공률은
Archimedes 방법을 사용하여 측정하였고, 시편의 개기공률 과 기공 크기의 분포는 수은 함침법을 이용한 Porosimetry (AutoPore IV 9500, Micromeritics, Norcross, GA, USA)를 사용하여 분석하였다. 제조된 시편의 미세조직은 주사전자 현미경 (SEM, S-4300, Hitachi Co., Japan)을 사용하여 관 찰하였고, 시편의 결정상은 $\mathrm{CuK \alpha}$ 선을 사용하여 $\mathrm{X}$-선 회 절 분석 $(\mathrm{XRD}, \mathrm{D} 8$ Discover, Bruker $\mathrm{AXS} \mathrm{GmbH}$, Germany)을 수행하였다. 곡강도 측정을 위한 시편은 2000 번 연마지를 사용하여 시편의 표면을 연마하여 준비하였 고, 만능시험기 (Instron 4461, Norwood Co., USA)를 사 용하여 $30 \mathrm{~mm} \mathrm{span}$ 의 치구를 사용하여 $0.5 \mathrm{~mm} / \mathrm{min}$ 의 cross-head 속도로 3점 곡강도 방법으로 측정하였다.

\section{3. 결과 및 고찰}

Fig. 1 은 $1000^{\circ} \mathrm{C}$ 의 온도에서 2 시간 동안 소결 제조된 시 편의 XRD 결과를 보여주고 있다. 벤토나이트와 활석이 첨가되지 않은 B0T0 시편은 카올린과 첨가제인 소듐보레

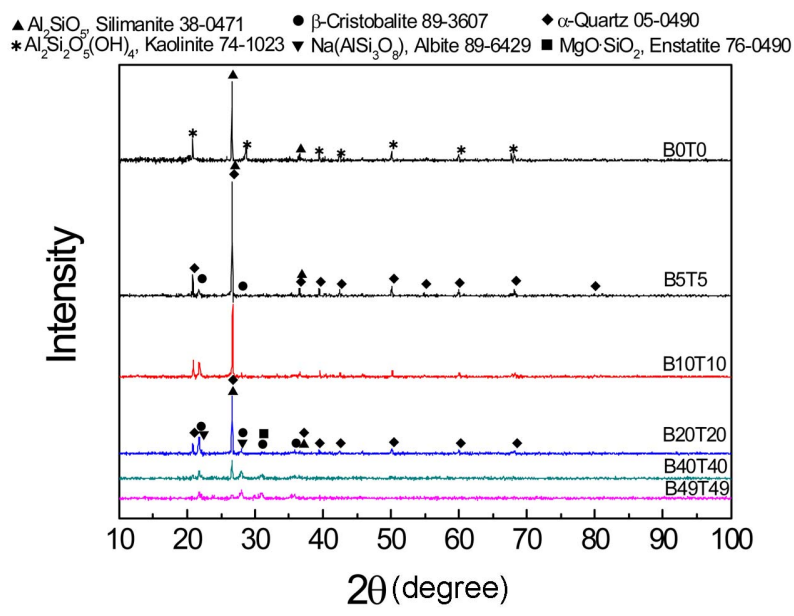

Fig. 1. XRD patterns of clay-based membranes.

Table 1. Sample Designation and Batch Composition of Clay-based Membranes

\begin{tabular}{|c|c|c|c|c|c|}
\hline \multirow{2}{*}{ Sample Designation } & \multicolumn{4}{|c|}{ Batch Composition (wt\%) } & \multirow{2}{*}{$(\mathrm{B}+\mathrm{T}) /(\mathrm{K}+\mathrm{B}+\mathrm{T})$} \\
\hline & Kaolin $^{\dagger}$ & Bentonite $^{*}$ & Talc* & Sodium Borate ${ }^{\S}$ & \\
\hline B0T0 & 98 & 0 & 0 & 2 & 0 \\
\hline B5T5 & 88 & 5 & 5 & 2 & 0.1 \\
\hline B10T10 & 78 & 10 & 10 & 2 & 0.2 \\
\hline B20T20 & 58 & 20 & 20 & 2 & 0.4 \\
\hline B40T40 & 18 & 40 & 40 & 2 & 0.8 \\
\hline B49T49 & 0 & 49 & 49 & 2 & 1 \\
\hline
\end{tabular}

Kaolin: extra pure, Samchun Pure Chemical Co. Ltd., Pyongtak, Korea.

*Bentonite: chemical pure, Yakuri Pure Chemicals C. Ltd., Kyoto, Japan.

*Talc: chemical pure, Samchun Pure Chemical Co. Ltd., Pyongtak, Korea.

${ }^{\S}$ Sodium borate: $\mathrm{Na}_{2} \mathrm{~B}_{4} \mathrm{O}_{7} \cdot 10 \mathrm{H}_{2} \mathrm{O}$, Samchun Pure Chemical Co., Ltd., Pyongtak, Korea. 

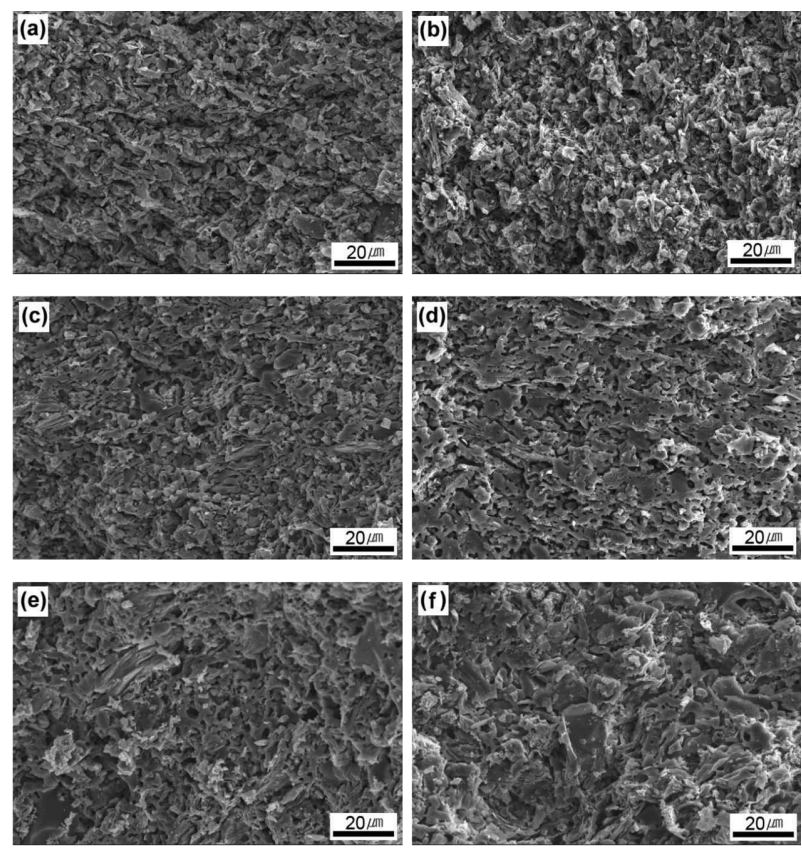

Fig. 2. Typical fracture surfaces of clay-based membranes sintered at $1000^{\circ} \mathrm{C}$ for $2 \mathrm{~h}$ in air: (a) B0T0, (b) B5T5, (c) B10T10, (d) B20T20, (e) B40T40, and (f) B49T49 (refer to Table 1).

이트만으로 제조하여 열처리 하였기 때문에, silimanite와 kaolinite로 이루어져있고, 벤토나이트와 활석이 $20 \mathrm{wt} \%$ 이 하로 첨가된 시편은 siliminite, $\alpha$-qurtz, $\beta$-croistobalite로 이루어져 있다. 벤토나이트와 활석의 함량이 $40 \mathrm{wt} \%$ 이 상인 시편의 경우, silimanite, $\alpha$-qurtz, $\beta$-croistobalite, albite, enstatite로 이루어져 있다. 이는 출발원료로 사용된 카올 린, 벤토나이트 및 활석이 열처리되면서 카올린의 알루미 늄과 벤토나이트의 나트륨 성분 등이 반응하여 albite $\left(\mathrm{NaAlSi}_{3} \mathrm{O}_{8}\right)$ 상이 나타났다. 한편, 벤토나이트와 활석의 함 량이 증가하고, 카올린의 함량이 감소됨에 따라 전반적으 로 silimanite 결정상의 peak intensity가 작아지는 반면에 $\alpha$-quartz의 양이 증가되는 것을 B40T40 시편과 B49T49 시편에서 관찰하였다.

Fig. 2는 점토기반 분리막에서 벤토나이트와 활석의 조 성 비율 변화에 따른 미세조직의 변화를 보여준다. 모든 조성의 시편들은 $~ 1.0 \mu \mathrm{m}$ 의 미세기공으로 이루어진 균일 한 미세구조를 보여준다. 벤토나이트와 활석이 포함되지 않은 B0T0 시편에서는 미세한 입자들로 이루어진 미세조 직이 얻어졌다. 반면에, B49T49 시편에서는 조대한 입자 들로 이루어진 미세조직이 얻어졌다. 이는 출발원료로 사 용한 벤토나이트와 활석의 입자가 카올린에 비해 상대적 으로 조대하기 때문에 $~ 10 \mu \mathrm{m}$ 크기의 입자들로 이루어 진 미세조직이 얻어졌다. Fig. 3는 점토기반 세라믹 분리 막의 고배율 미세조직을 보여준다. 벤토나이트와 활석이
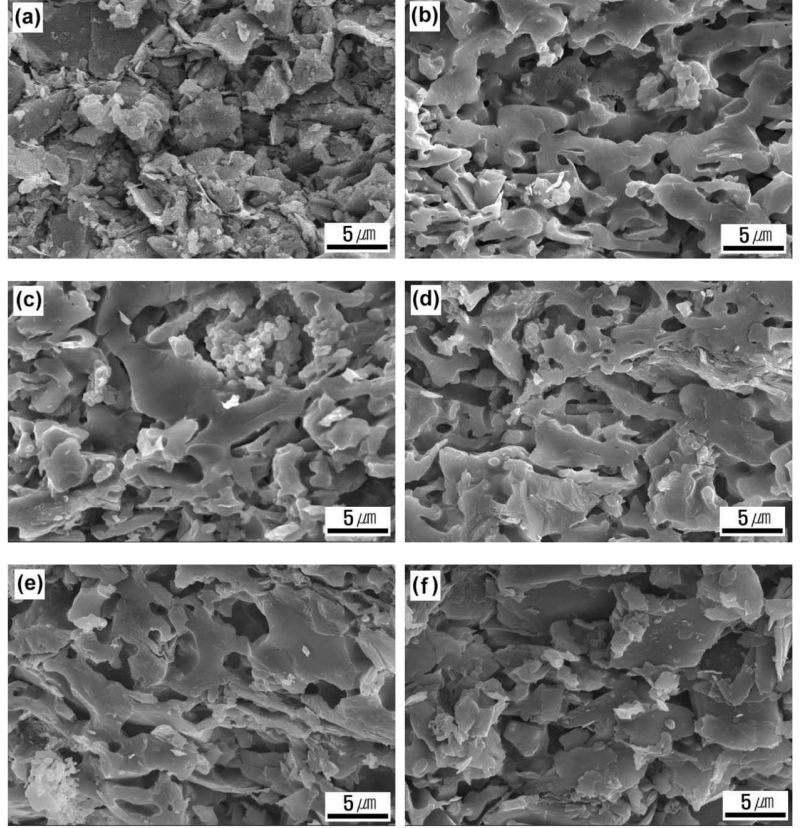

Fig. 3. Pore structures of clay-based membranes sintered at $1000^{\circ} \mathrm{C}$ for $2 \mathrm{~h}$ in air: (a) B0T0, (b) B5T5, (c) B10T10, (d) B20T20, (e) B40T40, and (f) B49T49 (refer to Table 1).

포함되지 않은 B0T0 시편은 카올린 입자들이 견고한 결 합을 형성시키지 못한 미세구조를 보여준다. 카올린과 첨 가제인 소듐보레이트만을 사용하여 소결한 시편은 판상 의 카올린 입자들과 소듐보레이트로 인해 형성된 유리상 이 점토입자에 견고한 결합을 형성시키지 못하여 입계파 괴를 보이고, 기공을 충분히 채우지 못해 기공벽에 잔류 기공이 남아 있어 다른 시편들에 비해 상대적으로 작은 입자간 기공이 많이 관찰되었다. 한편, 벤토나이트와 활 석의 조성이 각각 $5 \mathrm{wt} \%$ 이상 첨가된 시편에서는 판상 형상의 점토 입자들이 견고하게 결합된 미세구조를 보여 준다. 결합제로 첨가한 소듐보레이트는 $750^{\circ} \mathrm{C}$ 에서 녹기 때 문에 본 연구에서의 $1000^{\circ} \mathrm{C}$ 열처리는 첨가제를 충분히 녹 일 수 있었으며, 그로 인해 용해된 소듐보레이트는 카올린 입자들을 접합하는 결합제 역할을 하였다. ${ }^{14)}$ 소결시 용융된 소듬보레이트 및 카올린 원료내에 존재하는 $0.04 \mathrm{wt} \%$ 의 염 소, $0.05 \mathrm{wt} \%$ 의 철, $0.005 \mathrm{wt} \%$ 의 중금속 및 $0.0002 \mathrm{wt} \%$ 의 비소와 같은 불순물에 의해 형성된 유리상이 점토 입자 들간의 결합력을 강하게 하였으며, 결합제로 첨가한 소듐 보레이트는 소결시 작은 부피의 수축을 하면서 점성의 액 상으로 변화되어 점토 입자들을 견고하게 결합시켰다. ${ }^{14,20)}$ 용융된 소듐보레이트로 인해 점토 입자들이 강하게 결합 되어 있고, 그 결과로 시편의 입내파괴를 관찰 할 수 있 다. 벤토나이트와 활석의 함량을 $10 \sim 80 \%$ 범위로 첨가한 경우 (B5T5 B40T40), 점토광물들이 소듐보레이트로 잘 


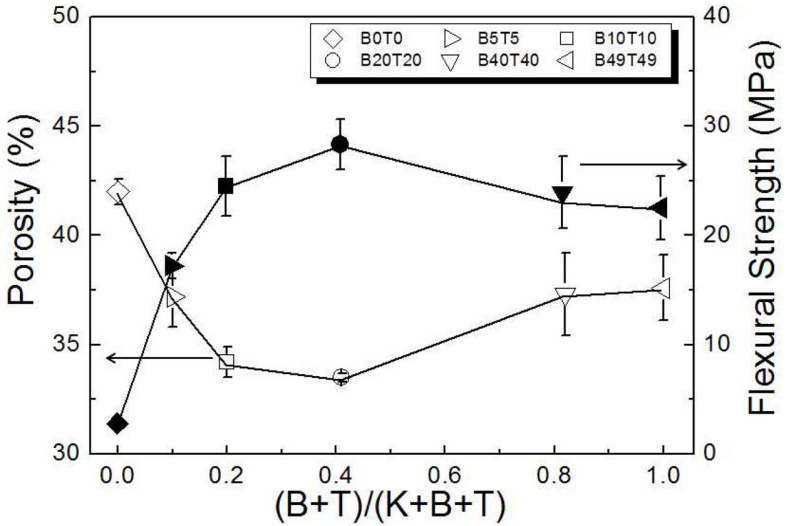

Fig. 4. Effect of $(B+T) /(K+B+T)$ ratio on porosity and flexural strength of clay-based membranes $(\mathrm{K}, \mathrm{B}$, and $\mathrm{T}$ denote kaolin, bentonite, and talc, respectively.).

결합이 이루어져 입내파괴를 보여준다. 반면에, 벤토나이 트와 활석의 함량을 $98 \%$ 첨가하였을 때 (B49T49)는 결 합제로 사용된 소듐보레이트가 대립 점토광물을 충분히 결합시키지 못하여 입계파괴를 보여준다.

Fig. 4 는 $1000^{\circ} \mathrm{C}$ 에서 2 시간 동안 소결 제조한 점토기반 분리막의 점토조성 변화에 따른 기공률과 곡강도 변화를 보여준다. $(\mathrm{B}+\mathrm{T}) /(\mathrm{K}+\mathrm{B}+\mathrm{T})$ 의 비율이 0 에서 0.4 로 증가 함에 따라 기공률은 $42.0 \%$ 에서 $33.5 \%$ 로 감소하고, 곡강 도는 $2.8 \mathrm{MPa}$ 에서 $28.3 \mathrm{MPa}$ 로 증가하였다. 또한, $(\mathrm{B}+\mathrm{T}) /$ $(\mathrm{K}+\mathrm{B}+\mathrm{T})$ 의 비율이 0.4 에서 1.0 으로 증가함에 따라 기 공률은 $33.5 \%$ 에서 $37.6 \%$ 로 증가하였고, 곡강도는 28.3 $\mathrm{MPa}$ 에서 $22.5 \mathrm{MPa}$ 로 감소하였다. 기공률이 증가하면 곡 강도가 감소하고, 기공률이 감소하면 곡강도가 증가하는 경향은 다공질 세라믹스의 곡강도가 기공률에 주로 의존 하기 때문이다. ${ }^{2,6,8,10)}(\mathrm{B}+\mathrm{T}) /(\mathrm{K}+\mathrm{B}+\mathrm{T})$ 의 비율이 0 인 시 편에서는 기공률이 $42.0 \%$ 로 점토기반 멤브레인에서 가장 높은 기공률을 나타냈다. 한편, $(\mathrm{B}+\mathrm{T}) /(\mathrm{K}+\mathrm{B}+\mathrm{T})$ 의 비 율이 0.4 인 시편에서는 $33.5 \%$ 로 가장 낮은 기공률을 나 타냈다. 이는 첨가제로 넣은 소듐보레이트와 출발원료인 카올린에 포함된 $\mathrm{SiO}_{2}$ 로 인해 소결온도에서 형성된 액상 이 점성유동 (viscous flow)에 의해 입자들 사이 및 내부 의 기공을 부분적으로 채우면서 치밀화가 일어났기 때문 이다. 본 연구에서는 벤토나이트와 활석의 조성을 변화하 여 점토기반 분리막의 기공률을 $33.5 \sim 42.0 \%$ 범위 내에 서 제어할 수 있었다.

한편, 곡강도는 일반적으로 벤토나이트와 활석의 함량 이 증가할수록 강도가 커지는 경향이 있지만 ${ }^{21)}$ 본 연구 에서는 $(\mathrm{B}+\mathrm{T}) /(\mathrm{K}+\mathrm{B}+\mathrm{T})$ 의 비율이 0.4 에서 $28.3 \mathrm{MPa}$ 의 최고 높은 곡강도 값을 보이다가 $(\mathrm{B}+\mathrm{T}) /(\mathrm{K}+\mathrm{B}+\mathrm{T})$ 의 비 율이 0.4를 넘어선 시편들 (B40T40, B49T49)에서 강도값 이 감소하는 경향을 보여주고 있다. $(\mathrm{B}+\mathrm{T}) /(\mathrm{K}+\mathrm{B}+\mathrm{T})$ 의 비율이 0.4 이상인 시편에서 강도가 감소하는 이유는

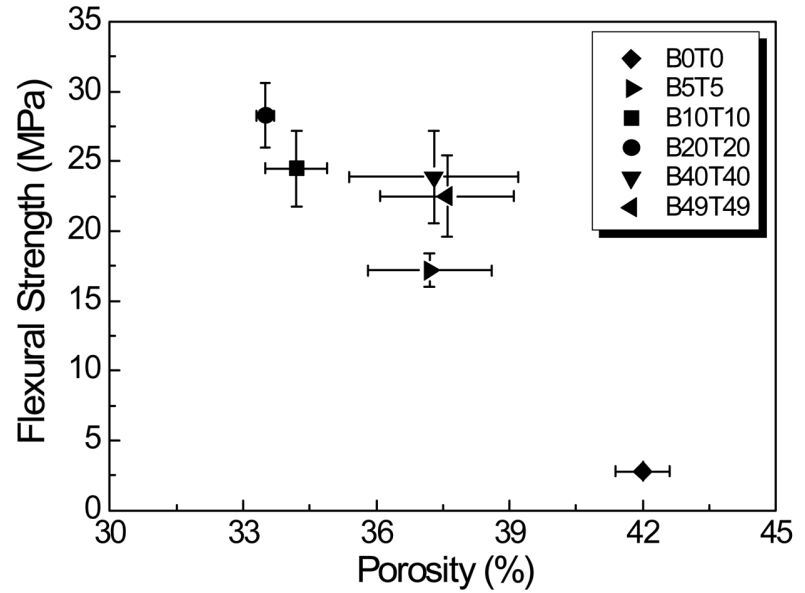

Fig. 5. Flexural strength as a function of porosity for the claybased membranes sintered at $1000^{\circ} \mathrm{C}$ in for $2 \mathrm{~h}$ air.

(1) 카올린의 함량이 감소하므로 이에 따른 $\mathrm{SiO}_{2}$ 의 함량 이 감소되어 점성유동 (viscous flow)이 활발히 일어나지 않아 치밀화가 충분치 못하여 기공률이 증가하였기 때문 이고, (2) Fig. 1의 XRD에서 보듯이 $(\mathrm{B}+\mathrm{T}) /(\mathrm{K}+\mathrm{B}+\mathrm{T})$ 의 비율이 0.1 에서 1.0 으로 증가할수록, $\beta$-cristobalite: $\alpha$ quartz의 비율이 $9: 1$ 에서 $6: 4$ 로 변화하면서, $\alpha$-quartz의 함량이 상대적으로 증가하였고, 이러한 상분율의 변화가 강도 저하의 원인으로 작용하였기 때문이다. 한편, $(\mathrm{B}+\mathrm{T}) /$ $(\mathrm{K}+\mathrm{B}+\mathrm{T})$ 의 비율이 0.4 에서는 $28.3 \mathrm{MPa}$ 의 가장 높은 곡 강도 값을 나타냈는데, 이는 Fig. 3의 (d)에서 보듯이 카 올린에 벤토나이트와 활석의 함량이 각각 $20 \mathrm{wt} \%$ 씩 포함 된 시편 (B20T20)은 다른 시편보다 소듐보레이트와 카올 린에 포함된 $\mathrm{SiO}_{2}$ 로 인해 소결온도에서 형성된 액상이 점 성유동 (viscous flow)에 의해 입자들의 기공을 감소 시켜 시편의 치밀화에 기여하였고, 유리상이 점토 입 자들을 강하게 결합시켰기 때문이다. 본 연구에서는 $(\mathrm{B}+\mathrm{T}) /(\mathrm{K}+\mathrm{B}+\mathrm{T})$ 의 비율이 0.4 일 때, $33.5 \%$ 의 기공 률에서 $28.3 \mathrm{MPa}$ 의 가장 높은 곡강도 값을 얻었다.

Fig. 5 는 $1000^{\circ} \mathrm{C}$ 에서 2 시간동안 소결하여 제조한 점토 기반 분리막의 기공률에 따른 곡강도를 보여준다. 제조된 점토기반 분리막은 $33.5 \sim 42.0 \%$ 기공률 범위에서 2.8 $28.3 \mathrm{MPa}$ 범위의 곡강도 값을 갖는다. 벤토나이트와 활석 이 첨가되지 않은 $\mathrm{B} 0 \mathrm{~T} 0$ 은 $42.0 \%$ 의 기공률에서 $2.8 \mathrm{MPa}$ 의 곡강도를 보여주는 반면, 카올린에 벤토나이트와 활석 을 첨가하여 제어한 점토기반 분리막은 $33.5 \sim 37.6 \%$ 범 위의 기공률에서 $17.2 \sim 28.3 \mathrm{MPa}$ 범위의 곡강도 값을 갖 는다. 다른 세라믹 분리막과 마찬가지로 본 연구에서 제 조된 분리막도 기공율이 증가함에 따라 곡강도가 낮아지 는 일반적인 경향을 보여준다. ${ }^{2,6,8,10)}$ 이는 세라믹 분리막 의 곡강도는 기공률에 의해 주된 영향을 받음을 나타낸 다. Saffaj ${ }^{22)}$ 등은 Moroccan 점토를 원료로 사용하여 세라 
믹 분리막을 제조하였고, 기공률 $35 \%$ 및 $42 \%$ 에서 각각 $12 \mathrm{MPa}$ 및 $10 \mathrm{MPa}$ 의 곡강도를 보고하였다. $\mathrm{Emani}^{23)}$ 등은 카올린을 원료로 사용하여 세라믹 분리막을 제조하였을 때의 곡강도는 기공률 $39 \%$ 에서 $11 \mathrm{MPa}$ 이었다. 본 연구에 서 고찰한 조성 중에서 $(\mathrm{B}+\mathrm{T}) /(\mathrm{K}+\mathrm{B}+\mathrm{T})$ 의 비율이 0.4 인 시편이 $34 \%$ 의 기공률과 $28.3 \mathrm{MPa}$ 의 가장 높은 곡강 도를 나타냈다. 이는 기존에 보고된 곡강도보다 우수한 값으로, 이러한 우수한 강도는 Fig. 2의 미세조직 관찰에 서 보듯이 벤토나이트와 활석의 비율을 제어함으로써 $\sim 1 \mu \mathrm{m}$ 의 미세 기공을 갖는 균일한 미세구조를 갖고 있 기 때문이다. 본 연구에서 비용효율이 높은 점토기반 분 리막의 우수한 기계적 특성을 향상하고 기공률을 향상시 키기 위해서는 벤토나이트와 활석의 조성을 제어하는 것 이 매우 중요함을 나타낸다. 결국, 점토기반 분리막에 저 비용의 점토 광물조성을 최적화 함으로서 추가적인 곡강 도 증진이 가능할 것으로 예상된다.

\section{4. 결 론}

카올린, 벤토나이트, 활석을 출발원료로 사용하고 첨가 제로 소듐보레이트를 첨가하여 $1000^{\circ} \mathrm{C}$ 의 온도에서 제조한 점토기반 분리막의 곡강도를 고찰하였다. 점토기반 분리 막에 벤토나이트와 활석을 첨가 제조한 시편은 $\sim 1.0 \mu \mathrm{m}$ 의 기공크기를 갖는 균일한 미세구조를 나타냈고, 벤토나이 트와 활석의 조성을 제어함으로써 기공율을 $34 \sim 42 \%$ 범 위에서 제어할 수 있었다. 벤토나이트와 활석의 함량이 증가할 때, 기공률이 감소하면 곡강도가 증가하고, 기공 률이 증가하면 곡강도가 감소하는 경향을 본 연구에서 보 였는데, 이는 다공질 세라믹스의 곡강도가 기공률에 주로 의존하기 때문이다.

본 연구에서 고찰한 조성 중에서 $(\mathrm{B}+\mathrm{T}) /(\mathrm{K}+\mathrm{B}+\mathrm{T})$ 의 비율이 0.4 인 시편이 $34 \%$ 의 기공률과 $28.3 \mathrm{MPa}$ 의 곡강 도를 나타냈다. 출발원료에서 벤토나이트와 활석의 조성 을 최적화함으로써 비용효율이 우수하고 친자연적인 점 토기반 분리막의 곡강도를 추가적으로 향상시키는 것이 가능할 것으로 판단된다.

\section{Acknowledgment}

본 연구는 한국기계연구원 부설 재료연구소 (Korea Institute of Materials Science, KIMS)의 연구비 지원으로 수행되었으며, 이에 감사 드립니다.

\section{REFERENCES}

1. C. E. Reid and E. J. Breton, "Water and Ion Flow Across Cellulosic Membranes," J. Appl. Polym. Sci., 1 [2] 133-43 (1959).
2. B. V. M. Kumar and Y.-W. Kim, "Processing and Polysiloxane-Derived Porous Ceramics: A Review," Sci. Tech. Adv. Mater., 11044303 (2010).

3. D. Y. Shin, S. M. Han, and S. G. Choi, "Synthesis of Ceramic Support for Immobilization of Microorganisms Using Fly Ash(in Korean)," J. Kor. Ceram. Soc., 39 [9] 857-62 (2002).

4. D.-K. Lim and E.-T. Kang, "Porous Materials from Waste Bottle Glasses by Hydrothermal Treatment(in Korean)," J. Kor. Ceram. Soc., 46 [3] 275-81 (2009).

5. J. Park, Y. Kim, and M. Jung, "Preparation of Porous SiC Ceramics Using Polycarbosilane Derivatives as Binding Agents(in Korean)," J. Kor. Ceram. Soc., 49 [5] 412-46 (2012).

6. K. M. Nam, Y. J. Lee, W. T. Kwon, S. R. Kim, H. M. Lim, H. Kim, and Y. Kim, "Preparation of $\mathrm{Al}_{2} \mathrm{O}_{3}$ Platelet and Its Mechanical/Thermal Characterization(in Korean)," J. Kor. Ceram. Soc., 49 [5] 438-41 (2012).

7. E.-J. Lee, J.-H. Ha, Y.-D. Kim, and I.-H. Song, "Effects of Pre-sintered Granules on the Characteristics of Porous Zirconia(in Korean)," J. Kor. Ceram. Soc., 49 [6] 566-74 (2012).

8. J. H. Eom, Y.-W. Kim, and I. H. Song, "Effect of SiC Filler Content on Microstructure and Flexural Strength of Highly Porous SiC Ceramics Fabricated from Carbon-filled Polysiloxane," J. Kor. Ceram. Soc., 49 [6] 625-30 (2012).

9. G. S. Park, Y.-H. Seong, J. H. Yu, S. K. Woo, and M. H. Han, "Fabrication and Mechanical Properties of High-strength Porous Supports for High Temperature Oxygen Transport Membranes(in Korean)," J. Kor. Ceram. Soc., 50 [6] 423-28 (2013).

10. J. H. Eom, Y.-W. Kim, and S. Raju, "Processing and Properties of Macroporous Silicon Carbide Ceramics: A Review," J. Asian Ceram. Soc., 1 [3] 220-42 (2013).

11. Y. H. Wang, X. Q. Liu, and G. Y. Meng, "Dispersion and Stability of $8 \mathrm{~mol} \%$ Yttria Stabilized Zirconia Suspensions for Dip-Coating Filtration Membranes," Ceram. Int., 33 102531 (2007).

12. K. A. Defriend, M. R. Wiesner, and A. R. Barron, "Alumina and Aluminate Ultrafiltration Membranes Derived Alumina Nanoparticles," J. Membr. Sci., 224 [1-2] 11-28 (2003).

13. H. Qi, Y. Fan, W. Xing, and L. Winnubst, "Effect of $\mathrm{TiO}_{2}$ Doping on the Characteristics of Macroporous $\mathrm{Al}_{2} \mathrm{O}_{3} / \mathrm{TiO}_{2}$ Membrane Supports," J. Eur. Ceram. Soc., 30 [6] 1317-25 (2010).

14. J. H. Eom, Y.-W. Kim, and I. H. Song, "Processing of Kaolin-based Microfiltration Membranes," J. Kor. Ceram. Soc., 50 [5] 341-47 (2013).

15. F. Bouzerara, A. Harabi, S. Achour, and A. Larbot, "Porous Ceramic Supports for Membranes Prepared from Kaolin and Doloma Mixtures," J. Eur. Ceram. Soc., 26 [9] 1663-71 (2006).

16. M. Kazemimoghadam and T. Mohammadi, "Preparation of Nano Pore Hydroxysodalite Zeolite Membranes Using of Kaolin Clay and Chemical Sources," Desalination, 278 [13] 438-42 (2011).

17. A. Yamaguchi, F. Uejo, T. Yoda, T. Uchida, Y. Tanamura, T. Yamashita, and N. Teramae, "Self-assembly of a Silica-sur- 
factant Nanocomposite in a Porous Alumina Membrane," Nat. Mater., 3 [5] 337-41 (2004).

18. C. R. Martin, "Nanomaterials: A Membrane-based Synthetic Approach," Science, 266 [5193] 1961-66 (1994).

19. C. R. Martin, "Membrane-based Synthesis of Nanomaterials," Chem. Mater., 8 [8] 1739-46 (1996).

20. K. Y. Lim, Y.-W. Kim, and I. H. Song, "Porous Sodium Borate-bonded SiC Ceramics," Ceram. Int., 39 6827-34 (2013).

21. S. Kumar and W.-L. Yong, "Effect of Bentonite on Compacted Clay Landfill Barriers," Soil Sediment Contam., 11
[90] 71-89 (2002).

22. N. Saffaj, M. Persin, S. A. Younsi, A. Albizan, M. Cretin, and A. Larbot, "Elaboration and Characterization of Microfiltration and Ultrafiltration Membranes Deposited on Raw Support Prepared from Natural Moroccan Clay: Application to Filtration of Solution Containing Dyes and Salts," Appl. Clay Sci., 31 [1-2] 110-19 (2006).

23. S. Emani, R. Uppaluri, and M. K. Purkait, "Preparation and Characterization of Low Cost Ceramic Membranes for Mosambi Juice Clarification," Desalination, 317 [15] 32-40 (2013). 